Article

\title{
Correlation of Rh Particle Size with CO Chemisorption: Effect on the Catalytic Oxidation of MTBE
}

\author{
Adrián Cervantes Uribe ${ }^{1, *}$, Gloria Alicia Del Angel Montes ${ }^{2}$, Gilberto Torres-Torres ${ }^{1} \mathbb{C}$, \\ Armando Vázquez-Zavala ${ }^{2}$, Federico González-García ${ }^{2}$, Adrián Cordero-García ${ }^{1}$ and \\ Reyna Ojeda-López ${ }^{2}$ \\ 1 División Académica de Ciencias Básicas, Universidad Juárez Autónoma de Tabasco, P.O Box 24, Km 1 \\ Carretera Cunduacán-Jalpa de Méndez, Cunduacán C.P. 86690, Tab., Mexico \\ 2 Departamento de Química, Universidad Autónoma Metropolitana-Unidad Iztapalapa, Av. San Rafael \\ Atlixco No. 186, Iztapalapa C.P. 09340, CDMX, Mexico \\ * Correspondence: huajoloyet@hotmail.com
}

Received: 28 June 2019; Accepted: 1 August 2019; Published: 7 August 2019

\begin{abstract}
This study was conducted to identify the correlation between the $\mathrm{CO}$ chemisorption (linear interaction and gem dicarbonyl) and the specific size of rhodium particles, and further to determine the influence of this relationship on the catalytic oxidation reaction of methyl tert-butyl ether (MTBE). During the synthesis, first, $\mathrm{TiO}_{2}$ was developed by the sol-gel method under acidic conditions. Second, Rh was deposited ( $1 \mathrm{wt} \%)$ by the incipient wetness impregnation method. Later, with the aim of controlling the particle size, the $\mathrm{Rh} / \mathrm{TiO}_{2}$ materials were crystallized at different reduction conditions during $3 \mathrm{~h}$ heat treatment. The results obtained by TEM micrographs indicated that the average particle size varies between 1.0 and $8.1 \mathrm{~nm}$, depending on the conditions of heat treatment. From the histogram analysis of each TEM micrograph, two correlations were made: (i) the gem-dicarbonyl interaction was typical of Rh particles $\leq 1.5 \mathrm{~nm}$, and (ii) a linear interaction, bridged interaction and dentate interaction were observed in particles $\geq 1.6 \mathrm{~nm}$. The gem-dicarbonyl interaction (particle size $\leq 1.5 \mathrm{~nm}$ ) was the most active in the oxidation reaction of MTBE.
\end{abstract}

Keywords: FTIR-CO (Fourier-Transform Infrared Spectroscopy-CO); $\mathrm{Rh} ; \mathrm{TiO}_{2} ; \mathrm{MTBE} ; \mathrm{CWAO}$ (Catalytic Wet Air Oxidation)

\section{Introduction}

Rhodium is a metal that has been widely used in various catalytic reactions in an active phase [1-3]. It is characterized by its easy dispersion on the surface of metal oxides [4], its metallic stability in oxidizing atmospheres [5] and the chemical interactions that can occur on its surface [6,7]. However, there is great interest in determining its interactions with species involved in catalyzed chemical reactions [8]; for instance, in the oxidation reaction of carbon monoxide [9]. Previous works have identified the interactions between $\mathrm{CO}$ and the surface of metallic rhodium supported on $\mathrm{TiO}_{2}$ using probe molecule FTIR spectroscopy [10]. There are three types of $\mathrm{CO}$ species adsorbed on rhodium: gem-dicarbonyl $\left(2 \mathrm{CO}-\mathrm{Rh}^{+}\right)$, linearly bound (CO-Rh) and bridged (CO-2Rh) [11]. In the gem-dicarbonyl interaction, $\mathrm{CO}$ species exhibit two types of vibration frequencies, which are symmetric and antisymmetric at $\sim 2100$ and $\sim 2030 \mathrm{~cm}^{-1}$ in the planes $(1,1,1)$ and $(1,1,0)$, respectively, while the vibration of the linear interaction is at $2060 \mathrm{~cm}^{-1}[12,13]$ in the plane $(1,1,0)[14]$.

In a recent study, Yu et al. [15], synthesized Rh, Rh-Mn and $\mathrm{Rh}-\mathrm{Mn}-\mathrm{Li} / \mathrm{SiO}_{2}$ catalysts for the CO hydrogenation reaction with the aim of analyzing the types of $\mathrm{CO}$ chemisorption which occur on the Rh surface. The conclusion was that the $2 \mathrm{CO}-\mathrm{Rh}^{+}$(gem-dicarbonyl) interaction is characteristic of a highly 
dispersed metal phase and is affected by the incorporation of another metal phase. The researchers suggest that the increase in catalytic performance observed is due to changes in the catalyst's ability for $\mathrm{CO}$ adsorption, $\mathrm{CO}$ insertion, $\mathrm{H}_{2}$ dissociation, hydrogenation, etc., which are mainly controlled by the states of $\mathrm{Rh}$. In addition, Caballero et al. [16], synthesized $\mathrm{Rh} / \gamma-\mathrm{Al}_{2} \mathrm{O}_{3}-\mathrm{Nd}_{2} \mathrm{O}_{3}$ catalysts for the hydrogen production reaction from methane. In this study, they mentioned that the $2 \mathrm{CO}-\mathrm{Rh}^{+}$ interaction is associated with small, well-dispersed rhodium crystals on the surface of the support. Therefore, the Rh particle size and dispersion on the support are important factors, affecting the type of $\mathrm{CO}$ chemisorption. Other researchers have also reported that thermal treatments at $500{ }^{\circ} \mathrm{C}$ improve $\mathrm{Rh}$ dispersion, favoring the gem-dicarbonyl interaction [16,17]. Additionally, Samolia et al. [18] found that Rh catalysts, treated at $300^{\circ} \mathrm{C}$, have linear interactions with carbon monoxide. In this context, the aim of the present work is to correlate the different Rh particle sizes with the types of $\mathrm{CO}$ chemisorption and their influence on the catalytic activity of MTBE oxidation.

\section{Materials and Methods}

All chemical reagents and solvents were analytical reagent grade and were used as received. All solutions were prepared with ultrapure water $(18 \mathrm{M} \Omega$ ) from a Millipore Milli-Q system.

\subsection{Synthesis of $\mathrm{TiO}_{2}$}

$\mathrm{TiO}_{2}$ was obtained by the sol-gel method under acidic conditions, as follows: a mixture of titanium isopropoxide (Aldrich, St. Louis, MI, USA, $97 \%$ by weight) and isopropanol (99.5\%, Aldrich) was kept under constant stirring for $30 \mathrm{~min}$; then, the $\mathrm{pH}$ of the mixture was adjusted to 3 with nitric acid (Aldrich, 70\% by weight). Afterward, water was added dropwise to the mixture. The amount of water added was calculated at a molar ratio of 1:6 with respect to the alkoxide. The resulting sol was aged for $48 \mathrm{~h}$, followed by the removal of the solvent by evaporation in a vacuum and then drying at $120^{\circ} \mathrm{C}$ for $12 \mathrm{~h}$. The xerogel was calcined at $500^{\circ} \mathrm{C}$ for $2 \mathrm{~h}$ under an air atmosphere with a heating rate of $2{ }^{\circ} \mathrm{C} \min ^{-1}$.

\subsection{Synthesis of $\mathrm{Rh} / \mathrm{Ti} \mathrm{O}_{2}$ Catalysts}

The $\mathrm{Rh} / \mathrm{TiO}_{2}$ catalysts with $1 \mathrm{wt} \%$ of $\mathrm{Rh}$ were prepared by the impregnation method. The necessary amount of $\mathrm{RhCl}_{3} 3 \mathrm{H}_{2} \mathrm{O}$ (99.99\%, Aldrich) was dissolved in deionized water at room temperature under magnetic stirring. The solution was transferred to the mixture of $\mathrm{TiO}_{2} /$ water and kept under vigorous stirring for $3 \mathrm{~h}$. The extraction of the solvent was carried out by evaporation under a vacuum at $60^{\circ} \mathrm{C}$ until the solvent was completely evaporated. The obtained powders were dried at $120^{\circ} \mathrm{C}$ for $12 \mathrm{~h}$ in a vacuum oven. The powders were heated at a rate of $2{ }^{\circ} \mathrm{C} \mathrm{min}^{-1}$ from room temperature and kept at $500{ }^{\circ} \mathrm{C}$ for $3 \mathrm{~h}$ under a flowing air atmosphere $\left(\mathrm{O}_{2} / \mathrm{N}_{2}, 2 \% / 98 \%\right)$ for the oxidization of the rhodium. Subsequently, the catalyst obtained $\left(\mathrm{Rh} / \mathrm{TiO}_{2}\right)$ was divided into four portions, identified as RhTi1, RhTi2, RhTi3 and RhTi4.

The powders were exposed in an atmosphere of $\mathrm{H}_{2}\left(3.6 \mathrm{~L} \mathrm{~h}^{-1}\right)$. Each catalyst received a different reduction heat treatment as follows:

- $\quad$ RhTi1 was reduced at $500{ }^{\circ} \mathrm{C}$ for $3 \mathrm{~h}$ with a heating rate of $1^{\circ} \mathrm{C} \mathrm{min}^{-1}$;

- $\quad$ RhTi2 was reduced at $500{ }^{\circ} \mathrm{C}$ for $3 \mathrm{~h}$ with a heating rate of $2^{\circ} \mathrm{C} \mathrm{min}^{-1}$;

- $\quad$ RhTi3 was reduced at $400{ }^{\circ} \mathrm{C}$ for $3 \mathrm{~h}$ with a heating rate of $2{ }^{\circ} \mathrm{C} \mathrm{min}^{-1}$;

- $\quad$ RhTi4 was reduced at $300^{\circ} \mathrm{C}$ for $3 \mathrm{~h}$ with a heating rate of $2^{\circ} \mathrm{C} \mathrm{min}^{-1}$.

Immediately afterwards, the catalysts RhTi3 and RhTi4 were cooled to $25^{\circ} \mathrm{C}$.

\subsection{Characterization}

To determine the Rh content, inductively coupled plasma optical emission spectrometry (ICP-OES) data was obtained using a Perking-Elmer 4200DV optical emission spectrometer, as reported by Liu et al. [19]. The morphology and structure of the particles were investigated using Tecnai G2 F30 
transmission electron microscopy (TEM). An energy dispersive X-ray spectrometer (EDX) coupled to TEM was used to analyze the elementary composition of the particles. The sizes of $\mathrm{Rh} / \mathrm{TiO}$ nanoparticles were obtained by measuring 200 particles for each catalyst. The crystalline phase composition of the obtained catalysts was recorded using X-ray diffraction (XRD) (Siemens D-500 instrument) with $\mathrm{Cu}-\mathrm{K} \alpha$ radiation $(\lambda=1.5418 \AA$ ). The reflection intensities were measured in the $2 \theta$ scan range of $20-70^{\circ}$ with a step size of $0.02^{\circ}$ and a scan speed of $4^{\circ} \mathrm{min}^{-1}$. The temperature-programmed reduction under an $\mathrm{H}_{2}$ atmosphere was performed in CHEMBET-300 (Co) equipment using $0.2 \mathrm{~g}$ of fresh catalyst by means of the following protocol: the catalyst was heated at $120{ }^{\circ} \mathrm{C}$ under nitrogen flow $\left(10 \mathrm{~mL} \mathrm{~min}^{-1}\right)$ during $60 \mathrm{~min}$. Then, the catalyst was cooled down to room temperature $\left(35^{\circ} \mathrm{C}\right)$, and a mixed gas flow $\left(5 \% \mathrm{H}_{2} / 95 \% \mathrm{~N}_{2}\right)$ was passed through the cell. The temperature-programmed reduction (TPR) prolife was registered using a heating program of $10{ }^{\circ} \mathrm{C} \mathrm{min}^{-1}$ from room temperature up to $500{ }^{\circ} \mathrm{C}$ using a flow rate of the gas mixture of $10 \mathrm{~mL} \mathrm{~min}^{-1}$. The BET specific surface area was determined in an automatic Quantachrome Autosorb 3B analyzer. The nitrogen adsorption isotherms were carried out at $-196{ }^{\circ} \mathrm{C}$; prior to the nitrogen adsorption, the catalysts were outgassed overnight at $300{ }^{\circ} \mathrm{C}$. The specific surface area was calculated from the adsorption isotherms by the BET method. The CO adsorption studies were performed on a Nicolet 170 SX FTIR instrument. The catalysts were compressed into fine discs with a radius of $0.65 \mathrm{~cm}$. Subsequently, they were placed in a Pyrex glass cell with $\mathrm{CaF}_{2}$ windows coupled to gas inlet and outlet lines. The catalysts were reduced in-situ at $450{ }^{\circ} \mathrm{C}$ for $30 \mathrm{~min}$. Then, the reducing gas flow was interrupted by vacuum exchange $\left(1 \times 10^{-3} \mathrm{Torr}\right)$ at $300^{\circ} \mathrm{C}$ for $30 \mathrm{~min}$ to remove any further traces of gas. After cooling down to room temperature $\left(35^{\circ} \mathrm{C}\right)$, the $\mathrm{CO}$ was introduced into the system for $20 \mathrm{~min}$ to reach equilibrium adsorption. Finally, the excess carbon monoxide was evacuated, and a spectrum was recorded.

\subsection{Catalytic Activity}

The degradation of methyl tert-butyl ether (MTBE) in aqueous solution was examined in a batch-reactor with a capacity of $300 \mathrm{~mL}$ (Parr Instrument Co. Ltd., Moline, IL, USA). The reactor was equipped with a diverter tube for catalyst collection, a temperature control unit and a turbine propellant for agitation. The catalyst concentration $\left(1 \mathrm{~g} \mathrm{~L}^{-1}\right)$, initial concentration of MTBE $\left(300 \mathrm{mgL}^{-1}\right)$, temperature $\left(80^{\circ} \mathrm{C}\right)$, oxygen flow and stirring speed $(1000 \mathrm{rpm})$ were kept constant in each test. Previous test reactions showed that, under such conditions, the reaction was not controlled by the diffusion of oxygen into the liquid phase. All catalysts were filtered with a membrane filter $(0.45 \mu \mathrm{m})$ to remove particle suspensions prior to analysis. The analyte concentration was determined by gas chromatography (Varian Star 3400Cx) equipped with a Flame Ionization Detector (FID). The separation was achieved with an Agilent HP-INNOWax GC column $(30 \mathrm{~m}, 0.25 \mathrm{~mm}, 0.5 \mathrm{~mm}$, Agilent Technologies, Santa Clara, CA, USA). Mineralization was evaluated by measuring the total organic carbon (TOC) by the direct injection of the catalysts into a 5000 Shimadzu TOC-VCSH analyzer, (Shimadzu Corp., Tokyo, Japan). The initial rate $\left(-r_{i}\right)$ was calculated from the MTBE conversion as a function of time curves, using Equation (1):

$$
-r_{i}=\frac{\left(\frac{\Delta \operatorname{Conv}(\%)}{\Delta t}\right)\left(60[\text { pollutant }]_{i}\right)}{m}
$$

where $((\Delta \operatorname{Conv}(\%) \gamma \Delta t) \text { is the initial slope of the conversion curve, [pollutant }]_{\mathrm{i}}$ is the initial concentration of the pollutant $\left(\mathrm{mol} \mathrm{L}^{-1}\right)$ and $\mathrm{m}$ is the mass of the catalyst per liter $\left(\mathrm{g} \mathrm{L}^{-1}\right)$. The analysis of total organic carbon (TOC $\left(\mathrm{g} \mathrm{L}^{-1}\right)$ ) was done using Equation (2), where $\mathrm{TOC}^{0}$ and $\mathrm{TOC}^{60}$ at $\mathrm{t}=0 \mathrm{~min}$ and $\mathrm{t}=60 \mathrm{~min}$, respectively.

$$
\mathrm{X}_{\mathrm{TOC}}=\left(\frac{\mathrm{TOC}^{0}-\mathrm{TOC}^{60}}{\mathrm{TOC}^{0}}\right)
$$




\section{Results and Discussion}

\subsection{Catalysts Characterization}

The results obtained by ICP-OES show that the Rh content is $\sim 0.98 \%$ in all four catalysts. In each reaction test, chemical analysis was performed to corroborate that the metal was not lixiviated.

The reduction of the rhodium takes place at around $300{ }^{\circ} \mathrm{C}$, according to the reduction profile at the control temperature; see Figure 1. There is no consumption of hydrogen at higher temperatures; therefore, the thermal treatments proposed guaranteed the total reduction of the metal. The peak of TPR at low temperature belongs to well dispersed $\mathrm{Rh}_{2} \mathrm{O}_{3}$, which is easily formed, while the peak of TPR at high temperature belongs to the reduction of crystalline $\mathrm{Rh}_{2} \mathrm{O}_{3}$ or larger particles of $\mathrm{Rh}_{2} \mathrm{O}_{3}$ [20].

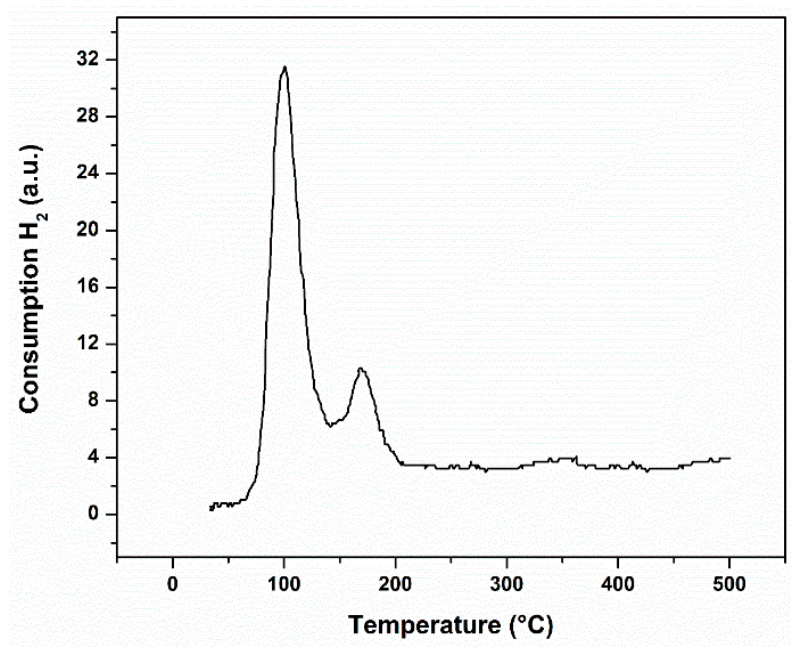

Figure 1. $\mathrm{H}_{2}$-temperature programmed reduction $\left(\mathrm{H}_{2}-\mathrm{TPR}\right)$ profile of the fresh catalyst.

The XRD diffractograms of $\mathrm{Rh} / \mathrm{TiO}_{2}$ catalysts (Figure 2a) show the main reflections, characteristics of the anatase-type structure $\left(2 \theta: 25.3,37.1,48.2,55.1,62.20^{\circ}\right)$, traces of the brookite phase $(2 \theta: 30.8$, $\left.36.1,37.2,46.03,48.3,55.60^{\circ}\right)$ and the rutile phase $\left(2 \theta: 27.4,36,41.2,54.30^{\circ}\right)$. This mixture of phases is characteristic of catalysts synthesized from titanium terisopropoxide [21].
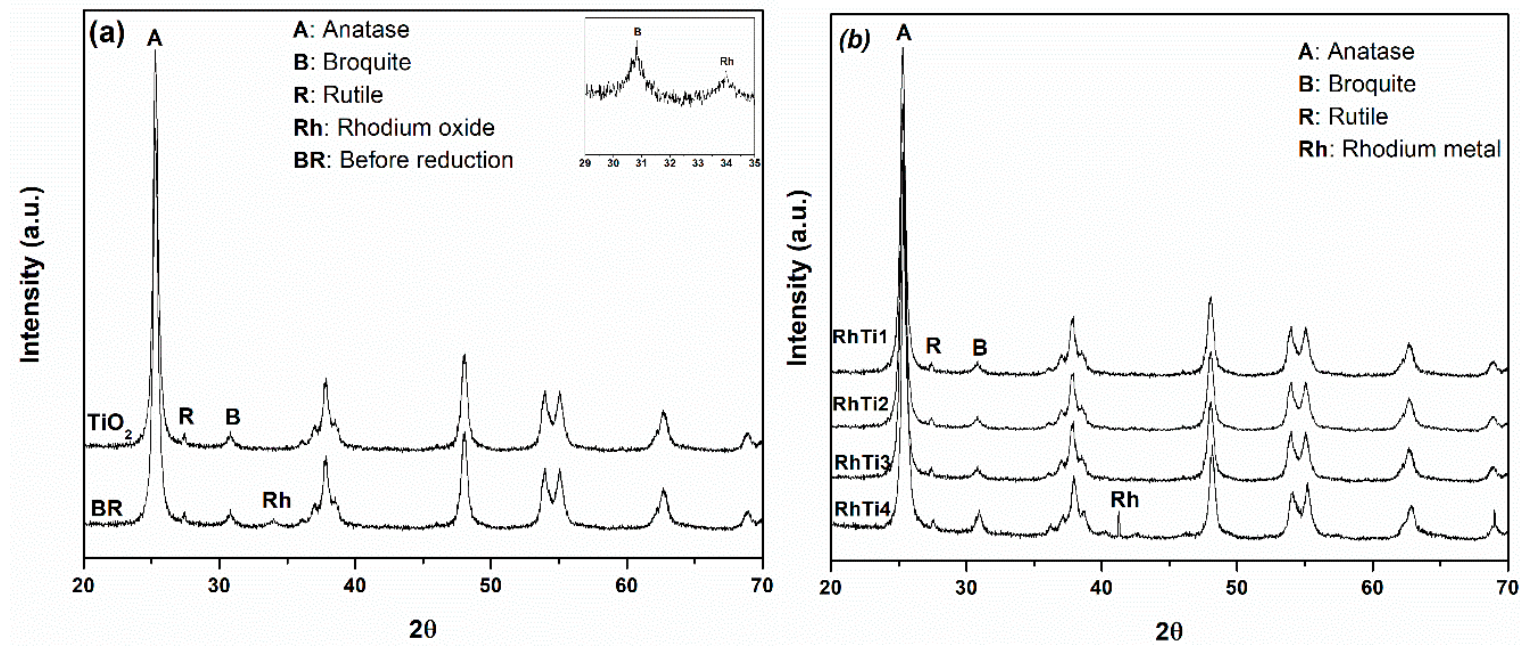

Figure 2. X-ray diffraction patterns of (a) $\mathrm{TiO}_{2}$ and catalyst before to reduction, (b) RhTi1, RhTi2 and RhTi3 and RhTi4 catalysts. 
Before the reduction process, the metal was in the $\mathrm{Rh}_{2} \mathrm{O}_{3}$ phase. It was possible to identify it by observing a diffraction in angle $2 \theta: 34^{\circ}$ [22] (see Figure 2a). The presence of rhodium oxide was corroborated by temperature-programmed reduction analysis. With respect to metallic rhodium, the typical diffractions of this metal were observed. Reflection peaks $\left(2 \theta: 41.06,47.7,69.80^{\circ}\right)$ attributed to Rh doping were observed only in the RhTi3 catalyst (see Figure $2 b$ ).

From Figure 3, the catalysts-i.e., $\mathrm{N}_{2}$ isotherms—can be classified as type IV, which is related to powders with a mesoporous structure. According to the International Union of Pure and Applied Chemistry (IUPAC) classification, the hysteresis loops are type $\mathrm{H} 2$, which is usually assigned to the powders with a non-uniform pore size or shape [23].

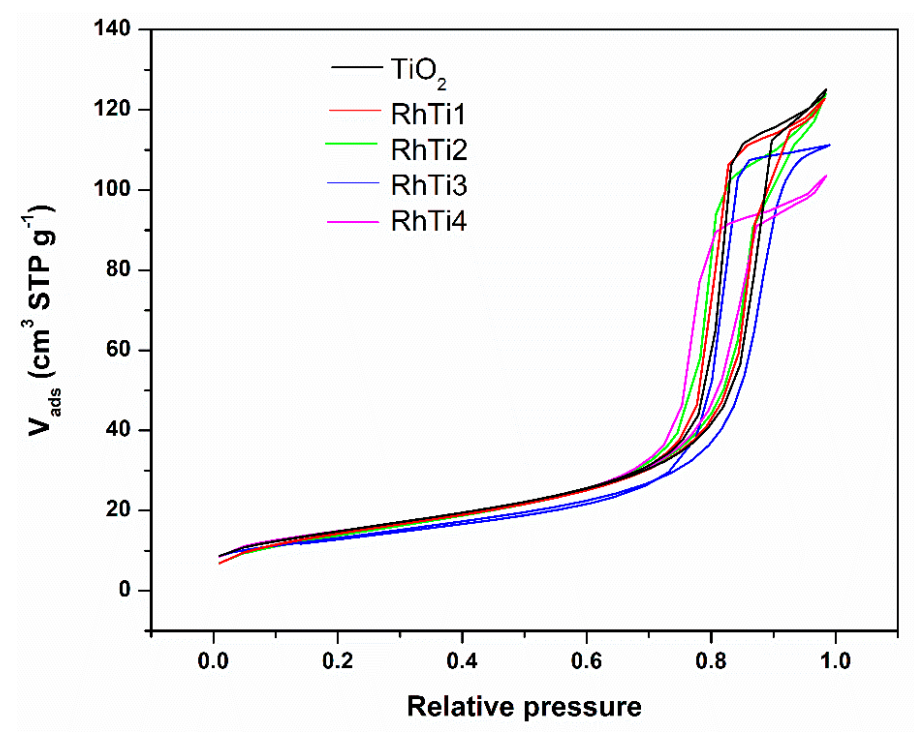

Figure 3. $\mathrm{N}_{2}$ isotherms of $\mathrm{TiO}_{2}$ and RhTi catalysts at $-196^{\circ} \mathrm{C}$.

The adsorption volume decreased for the RhTi3 and RhTi4 catalysts, and the pore diameter is reduced by the presence of metallic particles on the surface (see Figure 3). The surface area of the RhTi1 and RhTi2 catalysts is $2-4 \%$ less than that of $\mathrm{TiO}_{2}$, whereas it is $8-11 \%$ lower for RhTi3 and RhTi4 catalysts compared to $\mathrm{TiO}_{2}$, RhTi1 and RhTi2 (see Table 1).

Table 1. Net percentage, surface area, dispersion and metal particle size for each catalyst.

\begin{tabular}{|c|c|c|c|c|c|}
\hline Catalyst & $\operatorname{As}(B E T)\left(m^{2} g^{-1}\right)$ & $\mathrm{Rh}(\%)$ & $S\left(m^{2} g^{-1}\right)^{a}$ & $\mathrm{D}(\%)$ & $\mathrm{d}(\mathrm{nm})$ \\
\hline $\mathrm{TiO}_{2}$ & 54 & & & & \\
\hline RhTi1 & 53 & 0.985 & 435 & 98 & 1.1 \\
\hline RhTi2 & 51 & 0.986 & 370 & 83 & 1.3 \\
\hline RhTi3 & 50 & 0.987 & 120 & 27 & 4.1 \\
\hline RhTi4 & 49 & 0.983 & 60 & 13 & 8.1 \\
\hline
\end{tabular}

Figure 4 shows the TEM images of RhTi1, RhTi2, RhTi3 and RhTi4 catalysts. The average crystallite size (d) was calculated using the equation $\mathrm{d}=\sum \mathrm{n}_{\mathrm{i}} \mathrm{d}_{\mathrm{i}}^{3} / \sum \mathrm{n}_{\mathrm{i}} \mathrm{d}_{\mathrm{i}}^{2}$.

Rh particles on $\mathrm{TiO}_{2}$ supports can be seen clearly in Figure 4. Based on a measurement of 200 particles per catalyst, the mean particle sizes are estimated to be 1.09, 1.30, 4.1 and $8.10 \mathrm{~nm}$ for RhTi1, RhTi2, RhTi3 and RhTi4, respectively. The TEM images of catalysts RhTi1 and RhTi2 show that the rhodium particles are homogeneously dispersed on $\mathrm{TiO}_{2}$. The calculated particle sizes are characteristic of catalysts with a highly dispersed metallic phase and consequently a large metallic surface area. Rhodium particles in the RhTi3 catalyst have a larger diameter compared to the RhTi1 and RhTi2 catalysts, as shown in Figure 4. The micrograph of the RhTi4 catalyst shows large and heterogeneous 
particle sizes, which causes a low dispersion of the rhodium particles and low metallic surface area (see Table 1). The decrease of the heating rate from 2 to $1^{\circ} \mathrm{C} \mathrm{min}^{-1}$ decreased the particle size of $\mathrm{Rh}$. It has been reported that the rhodium particles generated in a thermal reduction process at $500{ }^{\circ} \mathrm{C}$ are stable and maintain their size. On the contrary, in treatments of $300{ }^{\circ} \mathrm{C}$, small particles can be obtained but tend to agglomerate in the cooling process [24]. However, when the maximum heating temperature was lowered from $500{ }^{\circ} \mathrm{C}$ to $300{ }^{\circ} \mathrm{C}$, the particle size increased. Therefore, the differences observed in $\mathrm{Rh}$ particles are due to the thermal treatment performed on each catalyst. The analysis of the interplanar distances shows that rhodium particles smaller than $2 \mathrm{~nm}$ exhibit the planes $(1,0,0)$ and $(1,1,1)$, while when particles are larger than $3 \mathrm{~nm}$, the plane $(1,1,0)$ predominates, as shown in Figure 4 .

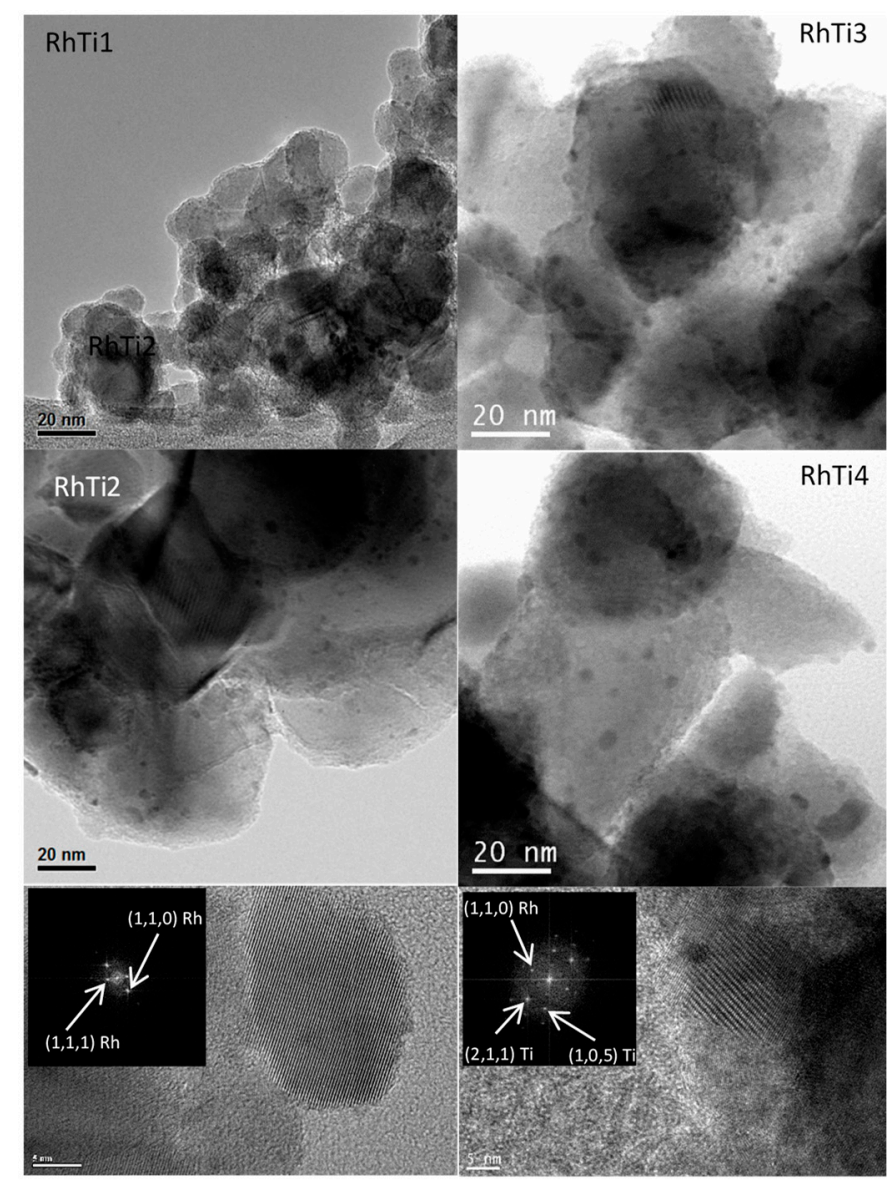

Figure 4. TEM images of RhTi1, RhTi2, RhTi3 and RhTi4 catalysts.

It has been established that primarily three different types of Rh sites exist on supports, depending upon the oxidation state and degree of dispersion of the rhodium (see Figure 5).<smiles>[O-]C[PH2][O-]</smiles>

I<smiles>[Mg][GeH3]</smiles>

II<smiles>[R18]C([R1])=O</smiles>

III<smiles>O=C[Pb][O-]</smiles>

IV

Figure 5. Scheme of three different primary types of Rh sites.

A geminal dicarbonyl species (species I) exhibits two sharp infrared bands near 2030 and $2100 \mathrm{~cm}^{-1}$ which correspond to the symmetric and asymmetric modes of $\mathrm{Rh}(\mathrm{CO})$, respectively, possibly forming on the edge atoms of supported Rh "rafts" containing $7 \mathrm{Rh}$ atoms [25]. Other types of site are linear 
monocarbonyl species (species II), with CO occupying a single surface site, which exhibits infrared of bands 2040 and $2075 \mathrm{~cm}^{-1}$ [26]; bridged carbonyl species (species III) CO between two adjacent metal atoms in the surface, which exhibit broad infrared band of 1840 and $1920 \mathrm{~cm}^{-1}$ [27]; and sometimes, the interaction of three molecules of $\mathrm{CO}$ with two particles of Rh (specie IV), which exhibits a broad infrared band between 1900-1920 $\mathrm{cm}^{-1}$ [28].

The infrared spectrum of the RhTil catalyst showed the presence of species I (see Figure 6a). Species I, II and III can be observed from the infrared spectrum of the RhTi2 catalyst (see Figure 6b). The RhTi3 catalyst (Figure 6c) also presented the species I, II and III; however, with a higher absorption band compared to RhTi2. Finally, the RhTi4 catalyst showed all four types of species in its infrared spectrum (see Figure 6d). Table 2 gives the relevant infrared data.
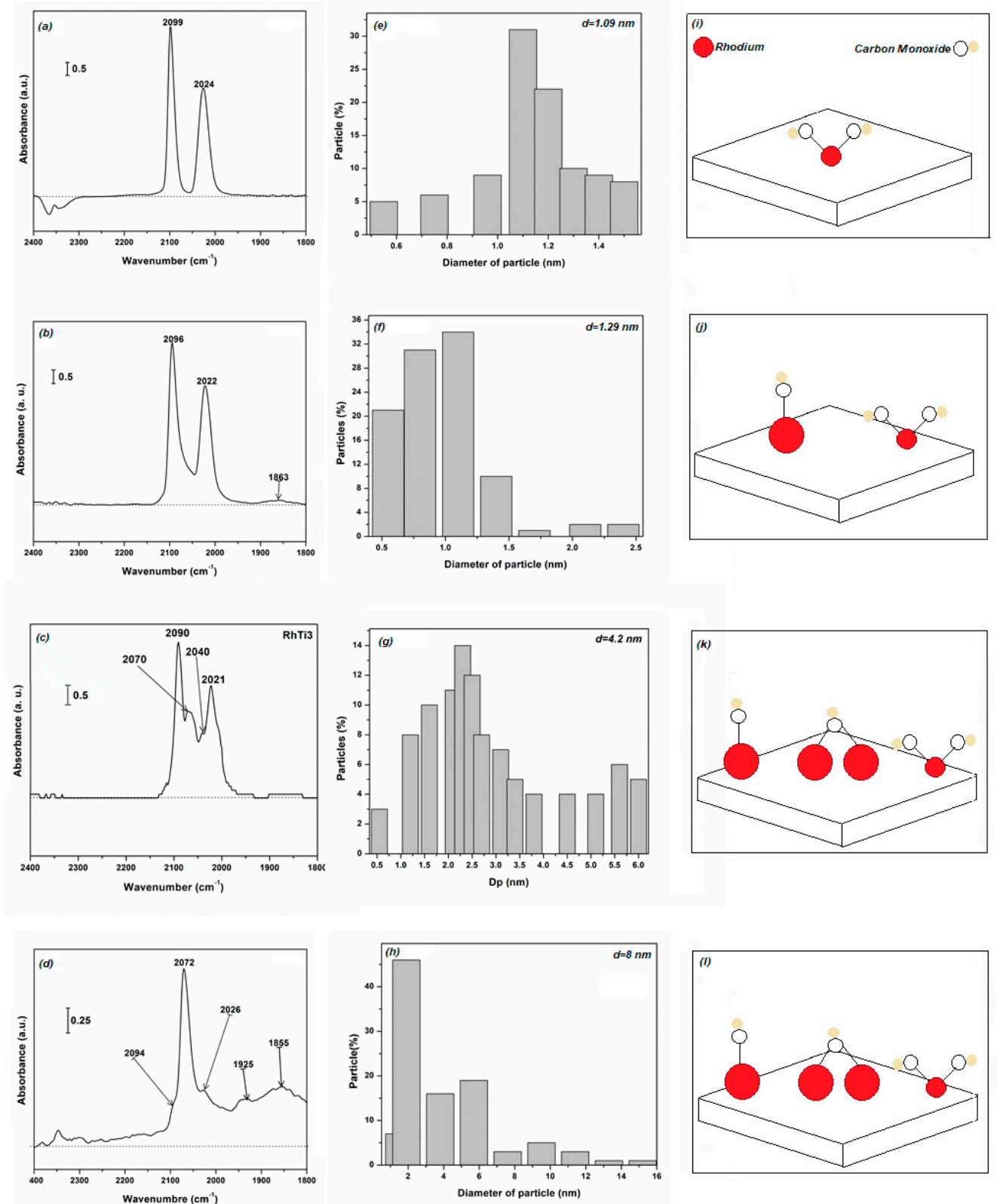

Figure 6. Infrared spectra of CO adsorption (a-d) for RhTi1, RhTi2, RhTi3 and RhTi4. Particle size distribution (e-h) for RhTi1, RhTi2, RhTi3 and RhTi4. Diagram of the interaction of CO with rhodium particles (i-1) for RhTi1, RhTi2, RhTi3 and RhTi4. 
Table 2. Infrared absorption frequencies of CO over supported rhodium catalysts.

\begin{tabular}{lcccc}
\hline \multirow{2}{*}{ Catalyst } & \multicolumn{4}{c}{ Frequency at $\mathbf{3 5}{ }^{\circ} \mathbf{C}$} \\
\cline { 2 - 5 } & Type I & Type II & Type III & Type IV \\
\hline RhTi1 & 2099,2024 & - & - & - \\
RhTi2 & 2096,2022 & 2070 & 1863 & - \\
RhTi3 & 2094,2026 & 2072 & 2025,1855 & - \\
RhTi4 & 2096,2022 & 2070 & 1863 & 1925 \\
\hline
\end{tabular}

The analysis of Rh particle size and the type of specie was attributed to the distribution of the nanoparticles on the support (Figure 6). According to the histogram of the catalyst RhTi1 (Figure 6e), most of the particles have an average size of $1.1 \mathrm{~nm}$; the rest were distributed in particle sizes of 1.2, 1.3, 1.4 and $0.6 \mathrm{~nm}$. In the infrared spectrum of this catalyst, only an absorption band associated to specie I was observed. Therefore, this indicates that this interaction is characteristic of particles with diameters $\leq 1.5 \mathrm{~nm}$, as illustrated in Figure 6i. For the RhTi2 catalyst, the highest percentage of metal particles was grouped around $1.1 \mathrm{~nm}$, with $0.6 \mathrm{~nm}$ being the least common. In addition, $4 \%$ of particles in this catalyst were observed to have sizes $\geq 2 \mathrm{~nm}$ (Figure $6 \mathrm{f}$ ). If specie II occurs in large particles ( $>2 \mathrm{~nm}$ ), these are not abundant in the RhTi2 catalyst, and so a weak infrared signal should be expected.

The $22 \%$ of the rhodium particles have a diameter in the range of $1.9-5.7 \mathrm{~nm}$, while $88 \%$ have diameters of 2-6 nm for RhTi3 (Figure 6g). Species II and III are observed on metal particles with sizes $\geq 2 \mathrm{~nm}$, as illustrated in Figure $6 \mathrm{k}$. In the RhTi4 catalyst, $88 \%$ of the rhodium particles have a diameter in the range of 1.9-5.7 nm, while $12 \%$ have diameters of 7-15 nm (Figure $6 \mathrm{~h}$ ). According to the infrared spectrum of this catalyst, species II predominates, as illustrated in Figure 61.

In short, specie I is present for particles with a size $\leq 1.5 \mathrm{~nm}$, whereas particle sizes $\geq 2 \mathrm{~nm}$ promote specie II; when there is no contact between rhodium particles, a bridged or toothed interaction with carbon monoxide is formed.

\subsection{Catalytic Activity}

Results of oxidation experiments (Table 3) indicated that MTBE mineralization is greater in the RhTi1 catalyst, following the order of efficiency between the catalysts of RhTi1 $>$ RhTi2 $>$ RhTi3 $>$ $\mathrm{RhTi} 4>\mathrm{TiO}_{2}$. With respect to the reaction rate, the RhTi1 catalyst was 1.5 times more active than RhTi2, 1.7 times more than RhTi3 and 1.8 times more active than RhTi4.

Table 3. Conversion, mineralization percentages and rate constants of methyl tert-butyl ether (MTBE) catalyzed by RhTi1, RhTi2, RhTi3 and RhTi4.

\begin{tabular}{|c|c|c|c|}
\hline Catalyst & $X_{\text {MTBE }}(\%)^{a}$ & $X_{\text {TOC }}(\%)^{a}$ & $-r_{i}\left(\mathrm{mmol} \mathrm{m}^{-2} \mathrm{~h}^{-1}\right)$ \\
\hline RhTi1 & 58 & 34 & 6.8 \\
\hline RhTi2 & 31 & 29 & 4.3 \\
\hline RhTi3 & 30 & 28 & 4.0 \\
\hline RhTi4 & 25 & 23 & 3.6 \\
\hline $\mathrm{TiO}_{2}$ & 19 & 16 & - \\
\hline
\end{tabular}

The identified products were methyl alcohol, tertbutyl alcohol, isopropyl alcohol and acetone. The catalysts with greater dispersion did not produce isopropyl alcohol (see Figure 5), and this suggests that the reaction route changed to one of greater efficiency, as supported by the analysis of total organic carbon.

Based on the selectivity (see Figure 7), the proposed reaction route for the catalyst with low dispersion is MTBE $>$ tert-butanol $>$ isopropyl alcohol $>$ acetone $>$ methanol. For the highly dispersed catalyst, the route is MTBE > terbutanol $>$ acetone $>$ methanol. In summary, rhodium particles with a smaller size provide more active sites, improving the activity and efficiency of the reaction. 

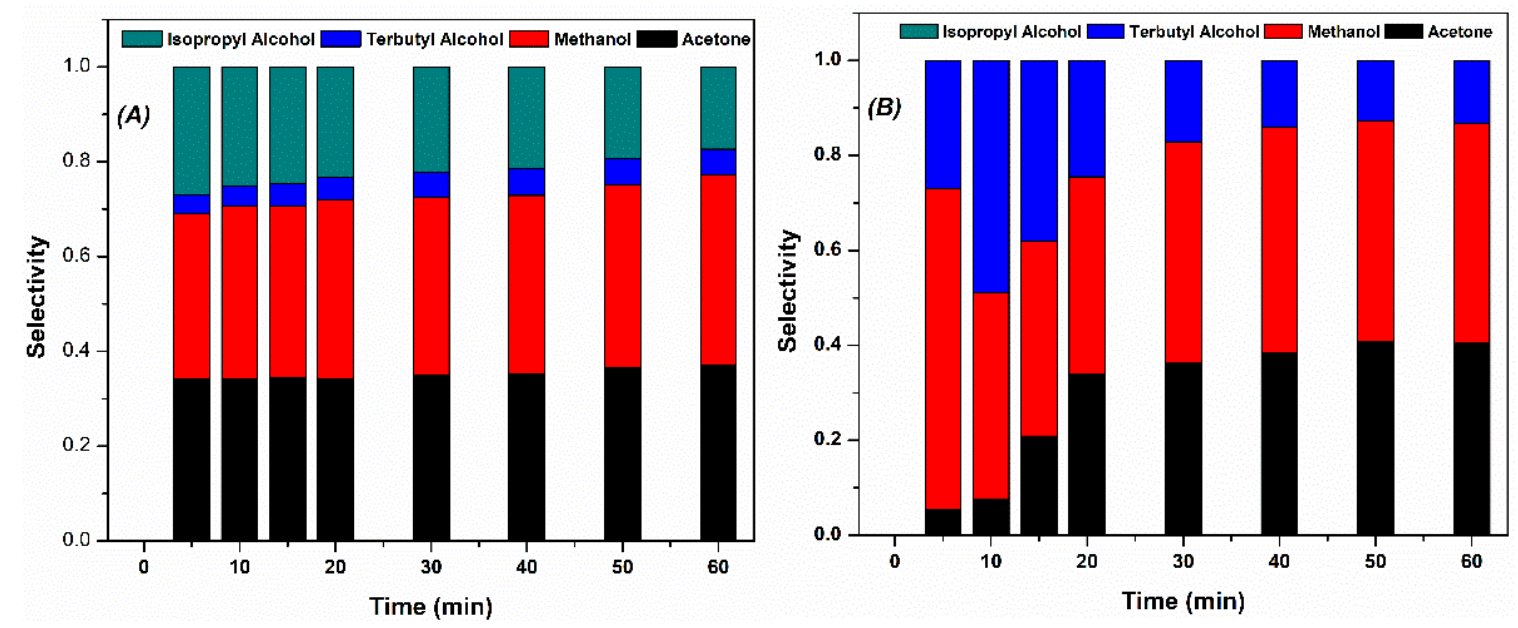

Figure 7. Selectivity of the products identified in the MTBE oxidation reaction. Highly dispersed catalyst (A), low dispersed catalyst (B).

Catalytic results indicated that catalysts with particles larger than $2 \mathrm{~nm}$ show less activity. To corroborate this phenomenon, the activity was evaluated in the presence of $300 \mathrm{ppm}$ MTBE and $50 \mathrm{ppm}$ of a by-product. The catalysts selected were RhTi1 and RhTi2. Table 4 shows the reaction rates with respect to the contaminant (MTBE).

Table 4. Catalytic activity based on by-products.

\begin{tabular}{ccccc}
\hline \multirow{2}{*}{ Catalyst } & \multicolumn{4}{c}{$-\mathbf{r}_{\mathbf{i}}\left(\mathbf{m m o l ~ m}^{-\mathbf{2}} \mathbf{h}^{\mathbf{- 1}}\right)$} \\
\cline { 2 - 5 } & Methanol & Acetone & Isopropyl Alcohol & Tert-Butanol \\
\hline RhTi1 & 6.6 & 6.5 & 6.3 & 6.1 \\
RhTi4 & 2.8 & 2.7 & 2.6 & 2.4 \\
\hline
\end{tabular}

The presence of a by-product decreases the activity of the RhTi1 catalyst; this effect is much greater in the case of the RhTi4 catalyst. Regarding the activity correlated with the FTIR-CO analysis, the rhodium particles $<1.5 \mathrm{~nm}$ exhibit two active sites for the degradation of the contaminant and by-products. In contrast, for particles that only expose an active site $(>1.5 \mathrm{~nm})$, the contaminant and by-products compete for the same site, consequently decreasing the reaction rate with respect to MTBE. Hence, the reaction rate correlates to the number of active sites present, which is fundamental for the oxidation of MTBE.

\section{Conclusions}

Specie I was found to be attributed to particle diameters $\leq 1.5 \mathrm{~nm}$, while particles with diameters between 1.5- $6 \mathrm{~nm}$ are associated to linear specie II, except when the rhodium particle is obstructed by another particle, resulting in bridged and dentate interactions. Therefore, the interaction type is a function of the diameter of $\mathrm{Rh}$ metal particles on $\mathrm{TiO}_{2}$. Also, it was seen that the absorption band of specie I decreases as the dispersion of the Rh particles decreases. However, when the metallic dispersion increases, specie I predominates, and consequently, the oxidation efficiency of MTBE increases, the preferred planes where $\mathrm{CO}$ is absorbed are key in catalytic activity. Hence, it can be stated that the improved efficiency obtained with the RhTi1 catalyst is ascribed to the changes in the surface properties of $\mathrm{Rh}$ particles on $\mathrm{TiO}_{2}$ caused by the modification of thermal treatment. We found that the best conditions for these purposes are $\mathrm{Rh} / \mathrm{TiO}_{2}$ reduced under hydrogen flow at $500{ }^{\circ} \mathrm{C}$ for $3 \mathrm{~h}$ with a heating rate of $1{ }^{\circ} \mathrm{C} \mathrm{min}^{-1}$. 
Author Contributions: A.C.U., reaction by chromatography; G.A.D.A.M., analysis by CO infrared; G.T.-T., synthesis of the samples; A.V.-Z., TEM microscopy; F.G.-G., analysis by X-ray diffraction; A.C.-G., analysis by TOC and TPR; R.O.-L. digestion of catalysts for analysis by ICP.

Funding: This work is financially supported by the Faculty of Chemical Sciences of the Universidad Autónoma Metropolitana (UAM) and CONACYT (Project SEP-CONACYT CB-2013-01-220191).

Acknowledgments: Special gratitude to the A. Vázquez, and the F. González for performing some characterization techniques. Adrian Cervantes Uribe thanks CONACYT for the support provided to accomplish Ph.D. Studies.

Conflicts of Interest: The authors declare no conflict of interest.

\section{References}

1. Hu, J.; Wu, X.; Huang, C.; Fan, W.; Qiu, X. Visible Light Photocatalytic Activity Induced by Rh(III) Modification on the Surface of BiOCl. Appl. Surf. Sci. 2016, 387, 45-50. [CrossRef]

2. Tóth, M.; Varga, E.; Oszkó, A.; Baán, K.; Kiss, J.; Erdohelyi, A. Partial Oxidation of Ethanol on Supported Rh Catalysts: Effect of the Oxide Support. J. Mol. Catal. A Chem. 2016, 411, 377-387. [CrossRef]

3. Nam, J.S.; Rong Kim, A.; Kim, D.M.; Chang, T.S.; Kim, B.S.; Bae, J.W. Novel Heterogeneous Rh-Incorporated Graphitic-Carbon Nitride for Liquid-Phase Carbonylation of Methanol to Acetic Acid. Catal. Commun. 2017, 99, 141-145. [CrossRef]

4. Faroldi, B.; Múnera, J.; Falivene, J.M.; Ramos, I.R.; García, Á.G.; Fernández, L.T.; Carrazán, S.G.; Cornaglia, L. Well-Dispersed Rh Nanoparticles with High Activity for the Dry Reforming of Methane. Int. J. Hydrog. Energy 2017, 42, 16127-16138. [CrossRef]

5. Oliviero, L.; Barbier, J.; Duprez, D.; Wahyu, H.; Ponton, J.W.; Metcalfe, I.S.; Mantzavinos, D. Wet Air Oxidation of Aqueous Solutions of Maleic Acid over Rh/CeO 2 Catalysts. Appl. Catal. B Environ. 2001, 35, 1-12. [CrossRef]

6. Wang, C.; Zheng, T.; Lu, J.; Wu, X.; Hochstadt, H.; Zhao, Y. Three-Way Catalytic Reactions on Rh-Based Catalyst: Effect of Rh/ceria Interfaces. Appl. Catal. A Gen. 2017, 544, 30-39. [CrossRef]

7. Bernal, S.; Blanco, G.; Calvino, J.J.; Cauqui, M.A.; Rodriguez-Izquierdo, J.M.; Vidal, H. Influence of the Preparation Procedure on the Chemical and Microstructural Properties of Lanthana Promoted $\mathrm{Rh} / \mathrm{SiO}_{2}$ Catalysts. A FTIR Spectroscopic Study of Chemisorbed CO. J. Alloys Compd. 1997, 250, 461-466. [CrossRef]

8. Back, S.; Lim, J.; Kim, N.-Y.; Kim, Y.-H.; Jung, Y. Single-Atom Catalysts for CO Electroreduction with Significant Activity and Selectivity Improvements. Chem. Sci. 2017, 594, 1-19.

9. Karelovic, A.; Ruiz, P. Improving the Hydrogenation Function of $\mathrm{Pd} / \gamma-\mathrm{Al}_{2} \mathrm{O}_{3}$ Catalyst by $\mathrm{Rh} / \gamma-\mathrm{Al}_{2} \mathrm{O}_{3}$ Addition in $\mathrm{CO}_{2}$ Methanation at Low Temperature. ACS Catal. 2013, 3, 2799-2812. [CrossRef]

10. Bódisa, J.; Németh, C.; Mink, J.; Keresztury, G.; Tétényi, P. Emission FT-IR Spectroscopic Study of Adsorbed Carbon Monoxide on Metal Powders and Supported Catalysts. J. Mol. Struct. 1997, 411, 179-182. [CrossRef]

11. Worley, S.D.; Mattson, A.; Caudlll, R. An Infrared Study of the Hydrogenation of CO on Supported Rh Catalysts. J. Phys. Chem. 1983, 87, 1671-1673. [CrossRef]

12. Diaz, A.L.; Quigley, W.W.C.; Yamamoto, H.D.; Bussell, M.E. Infrared Spectroscope and Temperature Programmed Desorption Study of $\mathrm{CO}$ on $\mathrm{Rh} / \mathrm{Al}_{2} \mathrm{O}_{3}$ Catalysts: Probing Overlayer and Support Sites. Langmuir 1994, 10, 1461-1471. [CrossRef]

13. Mink, J.; Gal, M.; Goggin, P.L.; Spencer, J.L. And Computerized Raman Studies of the Vibrational Spectra and Structure. J. Mol. Struct. 1986, 142, 467-472. [CrossRef]

14. Sant, R.; Wolf, E. Elementary-Step Modeling and Transient Studies of Co Oxidation $\mathrm{ON} \mathrm{Rh/SiO} 2$. Chem. Eng. Sci. 1990, 45, 3137-3147. [CrossRef]

15. Yu, J.; Mao, D.; Ding, D.; Guo, X.; Lu, G. New Insights into the Effects of Mn and Li on the Mechanistic Pathway for CO Hydrogenation on Rh-Mn-Li/SiO 2 Catalysts. J. Mol. Catal. A Chem. 2016, 423, 151-159. [CrossRef]

16. Caballero, M.; Del Angel, G.; Bonilla-Sánchez, A.; Rangel-Vázquez, I.; Arrieta, A.; Vázquez-Zavala, A.; Huerta, L.; Salgado, M. High Selectivity to Hydrogen on the Methane Decomposition over $\mathrm{Rh} / \gamma-\mathrm{Al}_{2} \mathrm{O}_{3}-\mathrm{Nd}_{2} \mathrm{O}_{3}$ Catalysts. Int. J. Hydrog. Energy 2016, 41, 23247-23259. [CrossRef]

17. Cuauhtémoc, I.; Del Angel, G.; Torres, G.; Angeles-Chavez, C.; Navarrete, J.; Padilla, J.M. Enhancement of Catalytic Wet Air Oxidation of Tert-Amyl Methyl Ether by the Addition of Sn and $\mathrm{CeO}_{2}$ to $\mathrm{Rh} / \mathrm{Al}_{2} \mathrm{O}_{3}$ Catalysts. Catal. Today 2011, 166, 180-187. [CrossRef] 
18. Samoila, P.; Boutzeloit, M.; Especel, C.; Epron, F.; Marécot, P. Relationship between the Structural Properties of Supported Bimetallic Pt-Rh Catalysts and Their Performances for Methylcyclopentane Ring Opening. J. Catal. 2010, 276, 237-248. [CrossRef]

19. Liu, H.; Lin, Y.; Ma, Z. $\mathrm{Rh}_{2} \mathrm{O}_{3} /$ mesoporous $\mathrm{MOx}-\mathrm{Al}_{2} \mathrm{O}_{3}(\mathrm{M}=\mathrm{Mn}, \mathrm{Fe}, \mathrm{Co}, \mathrm{Ni}, \mathrm{Cu}, \mathrm{Ba})$ Catalysts: Synthesis, Characterization, and Catalytic Applications. Chin. J. Catal. 2016, 37, 73-82. [CrossRef]

20. State, R.; Scurtu, M.; Miyazaki, A.; Papa, F.; Atkinson, I.; Munteanu, C.; Balint, I. Influence of metal-support interaction on nitrate hydrogenation over $\mathrm{Rh}$ and $\mathrm{Rh}-\mathrm{Cu}$ nanoparticles dispersed on $\mathrm{Al}_{2} \mathrm{O}_{3}$ and $\mathrm{TiO}_{2}$ supports. Arab. J. Chem. 2017, 10, 975-984. [CrossRef]

21. Hanaor, D.A.H.; Chironi, I.; Karatchevtseva, I.; Triani, G.; Sorrell, C.C. Single and Mixed Phase TiO 2 Powders Prepared by Excess Hydrolysis of Titanium Alkoxide. Adv. Appl. Ceram. 2012, 111, 149-158. [CrossRef]

22. Ye, J.Y.; Jiang, Y.X.; Sheng, T.; Sun, S.G. In-situ FTIR Spectroscopic Studies of Electrocatalytic Reactions and Processes. Nano Energy 2016, 29, 414-427. [CrossRef]

23. Thommes, M.; Kaneko, K.; Neimark, A.V.; Olivier, J.P.; Rodriguez-Reinoso, F.; Rouquerol, J.; Sing, K.S.W. Physisorption of Gases, With Special Reference to The Evaluation of Surface Area and Pore Size Distribution (Iupac Technical Report). Pure Appl. Chem. 2015, 87, 1051-1069. [CrossRef]

24. Varga, E.; Oszko, A. Stability and Temperature-Induced Agglomeration of Rh Nanoparticles Supported by $\mathrm{CeO}_{2}$. Langmuir 2016, 32, 2761-2770. [CrossRef] [PubMed]

25. Cavanagh, R.R.; Yates, J.T.J. Site Distribution Studies of Rh Supported on $\mathrm{Al}_{2} \mathrm{O}_{3}$ - $\mathrm{An}$ Infrared Study of Chemisorbed CO. J. Chem. Phys. 1981, 74, 4150-4155. [CrossRef]

26. Miessner, H.; Gutschick, D.; Ewald, H.; Miller, H. The Influence of Support on the Geminal Dicabonyl Species $\mathrm{Rh}_{1}(\mathrm{CO})_{2}$ on Supported Rhodium Catalysts: An Ir Spectroscopic. J. Mol. Catal. 1986, 36, 369-373. [CrossRef]

27. Hadjiivanov, K.; Ivanova, E.; Dimitrov, L.; Kno, H. FTIR Spectroscopic Study of CO Adsorption on Rh-ZSM-5: Detection of Rh-CO Species. J. Mol. Struct. 2003, 662, 459-463. [CrossRef]

28. Rice, C.A.; Worley, S.D.; Curtis, C.W.; Guin, J.A.; Tarrer, A.R. The Oxidation State of Dispersed Rh on Al2O3. J. Chem. Phys. 1981, 74, 6487-6497. [CrossRef]

(C) 2019 by the authors. Licensee MDPI, Basel, Switzerland. This article is an open access article distributed under the terms and conditions of the Creative Commons Attribution (CC BY) license (http://creativecommons.org/licenses/by/4.0/). 